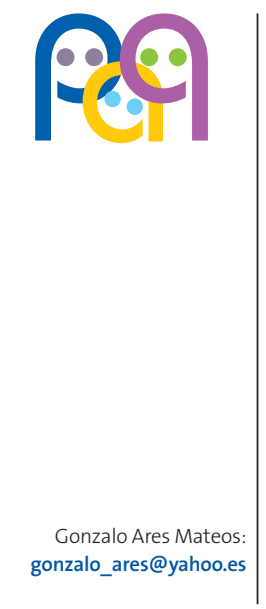

\title{
Editorial
}

\section{Continuidad asistencial del niño prematuro}

\author{
G. Ares Mateos
}

Servicio de Pediatría. Hospital Rey Juan Carlos. Móstoles, Madrid. España.

Antes se hablaba del "sietemesino", pero hoy día las madres afinan mucho a la hora de decir que su hijo es prematuro: "Ha nacido de 26 semanas", dicen.

El niño prematuro es el que nace antes de tiempo. Hemos puesto unos límites arbitrarios para definir que es aquél que nace antes de la semana 37 de gestación. Según este rasero, el que nace de 36 semanas y 6 días es prematuro, y corremos el riesgo de equipararlo al prematuro de 28 semanas, porque ambos son prematuros y para los padres "suena" igual, pero es evidente que su evolución es predeciblemente muy diferente.

Estamos acostumbrados a las estadísticas. Buscamos en la base de datos de la Sociedad Española de Neonatología de los menores de 1500 g y vemos que el porcentaje de hemorragia intraventricular grado IV en los niños de 26-27 semanas es del $10 \%^{1}$; y tal vez perdemos la perspectiva, tendiendo a generalizar. Aunque los porcentajes nos ayudan en cierta manera a poder pronosticar, no deben hacernos olvidar que cada niño prematuro es único, y existen muchos y diversos factores que van a influir en su evolución. Por un lado, su constitución genética; por otro, los cuidados prenatales y hospitalarios que haya recibido. Pero indudablemente es un proceso continuo, que sigue influido profundamente por el ámbito familiar en el que se desarrolle y su seguimiento en Atención Primaria.

Es por eso que en el seguimiento desde Atención Primaria (desde ese lado privilegiado del conoci- miento de las familias), la ayuda que se puede ofrecer es insustituible. Porque es desde ahí desde donde vamos a poder disipar falsos temores y encauzar la preocupación, valoración y seguimiento que precisan algunos trastornos.

Nacer muy prematuro es, sin duda, algo que marca el resto de la vida del niño. Los padres que han tenido un hijo muy prematuro saben del huracán emocional que supone, de lo duro de la estancia hospitalaria, con sus altibajos, sus momentos de ilusión y desilusión, la búsqueda de razones, la incomprensión...

Cuanto mayor es la prematuridad mayor es, en líneas generales, la morbilidad que puede presentarse a largo plazo. Pero también los prematuros tardíos (aquellos que nacen entre la semana 34 y 36 de gestación) requieren un seguimiento más estrecho por una mayor morbilidad, consecuencia de su relativa inmadurez ${ }^{2}$.

Cuando llega el feliz momento del alta, la alegría se mezcla con el temor. Y es el pediatra de Atención Primaria quien puede calmar los miedos infundados y orientar debidamente los problemas que pueden ir apareciendo, adelantándose a ellos en la medida de lo posible mediante la prevención.

Existen documentos muy valiosos para facilitar el seguimiento desde Atención Primaria, como es el programa de actividades preventivas y de promoción de la salud para niños prematuros que se ofrece en Previnfad ${ }^{3}$ y cuya actualización se presenta -en su primera parte- en este mismo número ${ }^{4}$. 
Se precisa una correcta valoración de la somatometría y del desarrollo psicomotor (atendiendo a la edad corregida y no a la edad cronológica). A su vez, conviene estar alerta ante trastornos motores, cognitivos, del comportamiento y psicológicos; y prestar la ayuda necesaria para el mantenimiento de la lactancia materna, especialmente en las altas tempranas. Hay que recomendar las vacunas incluidas en el calendario vacunal y aquellas que no lo están, pero que suponen un beneficio, más en estos niños, como la vacuna contra el rotavirus o el neumococo ${ }^{5}$. Es importante proporcionar información sobre la necesidad de seguir las recomendaciones en cuanto al uso de profilaxis contra el virus respiratorio sincitial que se hayan dado desde el hospital ${ }^{6}$. Y llevar seguimiento del tratamiento farmacológico que se incluya desde el alta, como la ferroterapia, conociendo los posibles efectos adversos y la necesidad de ajustar la dosis al peso creciente ${ }^{7}$.

Para mejorar el seguimiento de estos niños es muy positivo un contacto estrecho entre Atención Primaria y especializada. Ya antes del alta se debe contactar al menos telefónicamente con el pediatra que se encargará del seguimiento. Cuanta menos variabilidad exista entre las recomendaciones que se den desde un lado $u$ otro (muchas veces en temas que no están definitivamente resueltos, como la duración del tratamiento con hierro, cómo realizar la diversificación alimentaria, etc.) más fácil será para los padres tener unas pautas claras y concretas que seguir y reforzar su confianza en los servicios y profesionales sanitarios.

No se trata de duplicar intervenciones, sino de apoyar y asegurarse la continuidad del seguimiento para garantizar una evolución favorable de estos niños.

\section{BIBLIOGRAFÍA}

1. Figueras J, Pérez-Rodríguez J, Guzmán J, García P, Carrizosa T, Salas S, et al. y Sociedad Española de Neonatología. Análisis de resultados de los datos de morbimortalidad 2010. SEN1500 [en línea] [consultado el 19/05/2012]. Disponible en www.se-neonatal.es/ Portals/0/SEN-1500/Informe_Global_2010.pdf

2. de Jong $M$, Verhoeven $M$, van Baar AL. School outcome, cognitive functioning, and behaviour problems in moderate and late preterm children and adults: a review. Semin Fetal Neonatal Med. 2012;17(3):163-9.

3. Pallás CR. Programa de actividades preventivas y de promoción de la salud para niños prematuros con una edad gestacional menor de 32 semanas o un peso inferior a 1500 gramos. Del alta hospitalaria a los 7 años. En: Previnfad (AEPap)/PAPPS Infancia y adolescencia; marzo 2010 [en línea] [consultado el 18/05/2012]. Disponible en www.aepap.org/previn fad/pdfs/previnfad_menor32-1500_rec.pdf

4. Pallás Alonso CR. Grupo PrevInfad/PAPPS Infancia y Adolescencia. Actividades preventivas y de promoción de la salud para niños prematuros con una edad gestacional menor de 32 semanas o un peso inferior a 1500 g. Del alta hospitalaria a los siete años (1. a parte). Rev Pediatr Aten Primaria. 2012;14:155-68.

5. Comité Asesor de Vacunas. Calendario de Vacunas de la AEP, 2012 [en línea] [consultado el 20/05/2012]. Disponible en http://vacunasaep.org/profesionales/ calendario-de-vacunaciones-de-la-aep-2012

6. González de Dios J, Ochoa Sangrador C. La inmunización con palivizumab frente al virus respiratorio sincitial solo es coste-efectiva en prematuros con displasia broncopulmonar y en los meses de alto riesgo de la infección. Evid Pediatr. 2010;6:81.

7. Caserío Carbonero S, Pallás Alonso CR. Seguimiento del prematuro/gran prematuro en Atención Primaria. Rev Pediatr Aten Primaria. 2009;11 (Supl 17): s443-450. 